\title{
BMJ Open Resumption of sexual intercourse post partum and the utilisation of contraceptive methods in China: a cross- sectional study
}

\author{
Caixia Zhuang, Ting Li, Lei $\mathrm{Li}^{\odot}$
}

To cite: Zhuang C, Li T, Li L. Resumption of sexual intercourse post partum and the utilisation of contraceptive methods in China: a crosssectional study. BMJ Open 2019;9:e026132. doi:10.1136/ bmjopen-2018-026132

- Prepublication history and additional material for this paper are available online. To view these files, please visit the journal online (http://dx.doi. org/10.1136/bmjopen-2018026132).

Received 22 August 2018 Revised 3 February 2019 Accepted 7 February 2019

Check for updates

(c) Author(s) (or their employer(s)) 2019. Re-use permitted under CC BY-NC. No commercial re-use. See rights and permissions. Published by BMJ.

Obstetrics and Gynecology, Peking Union Medical College Hospital, Beijing, China

Correspondence to Dr Lei Li; lileigh@163.com

\section{ABSTRACT}

Objective This is a cross-sectional study that aimed to examine the resumption of sexual intercourse post partum, the utilisation of contraceptive methods and the influencing factors among Chinese women at a tertiary teaching hospital.

Design This is a questionnaire survey by written and online interview for participants.

Participants Based on medical records, we sent online questionnaires about postpartum sexual intercourse and contraception plans to 550 eligible women.

Main outcome measures Potential factors affecting postpartum sexual intercourse and utilisation of contraception were determined by analysis of epidemiological and clinical factors and sexual experiences during and after pregnancy.

Results of 550 eligible participants, 406 women (73.8\%) with a postpartum period of 8.5 months (range 6-10) completed the questionnaires; 146 of 406 (36.0\%) resumed sexual intercourse within 3 months, and 259 of $279(92.8 \%)$ used contraceptive methods. In univariate and multivariate analyses, sexual intercourse during pregnancy (adjusted $\mathrm{OR} 4.4,95 \% \mathrm{Cl} 2.8$ to 6.9 ) and resumption of menstruation (adjusted OR $2.5,95 \% \mathrm{Cl} 1.5$ to 4.3) were significant influencing factors in resumption of sexual intercourse within 3 months after childbirth. No factor was found to be associated with using contraceptive methods or the general resumption of sexual intercourse post partum. The questionnaire had good reliability and validity.

Conclusions Having sexual intercourse during pregnancy and resuming menstruation earlier were independent factors for resumption of sexual intercourse within 3 months after delivery. Almost all women who had postpartum sexual intercourse used various contraceptive methods.

\section{BACKGROUND}

Sexual activity and contraception are principal topics in women's health, and sexual dysfunction in pregnant women has generally been overlooked by physicians and other healthcare staff. ${ }^{1}$ As a widespread issue in reproductive health, postpartum sexual health has gained increasing attention
Strengths and limitations of this study

- For the first time we revealed the patterns of actual and desired contraceptive methods in postpartum Chinese women.

- A validated questionnaire was collected from pregnant women before and after the deliveries, and the potential risk factors for postpartum sexual experiences and contraception were considered.

- The main drawbacks of our study are recall and selection biases originating from enrolment of participants.

- There is no sufficient evidence to confirm the relationship between vaginal-penile intercourse and sexual well-being or relationship satisfaction.

worldwide. ${ }^{2}$ Although a precise definition remains elusive and postpartum sexual health cannot be separated theoretically from sexuality and sexual function, ${ }^{3}$ the resumption of sexual intercourse after delivery and the utilisation of contraceptive methods are significant features of postpartum sexual health. ${ }^{4}$ These features dramatically affect the quality of life and self-esteem of postpartum women. ${ }^{5}{ }^{6}$ Some studies have focused on resumption time, frequency of sexual intercourse and influence of fatigue on sexual intercourse. ${ }^{78}$ At present, the guidelines for clinical postpartum contraception recommend the initiation of effective contraception 3 weeks after delivery to avoid short pregnancy intervals. ${ }^{9}$ Decllines in unintended pregnany rates in Africa and in Western regions are attributed to implementation of family planning. ${ }^{10}$ However, knowledge on the patterns of actual and desired contraceptive methods in postpartum women is sparse.

Few data exist in China with regard to resumption of sexual intercourse post partum and utilisation of contraception. One study reported resumption of sexual intercourse post partum among migrant women 
in Shanghai. ${ }^{11}$ A report from Taiwan has revealed significant differences in sexual function shortly after delivery between groups based on the delivery method, tubal ligation, depression, pain, ethnicity and educational level, ${ }^{12}$ while a postpartum sexual health education programme has been shown to improve women's sexual health and sexual behaviour. ${ }^{13}$ In this cross-sectional study, we aimed to describe the patterns of postpartum sexual intercourse, utilisation of contraceptive methods and relevant influencing factors in Chinese women at a tertiary teaching hospital.

\section{METHODS}

\section{Patient and public involvement}

Participants who were interviewed had been informed that they had the right to freely withdraw from the study, for any reason, at any time prior to their data being integrated into the analysis. A preliminary study was conducted on 10 pregnant women at the Department of Obstetrics and Gynecology of the study hospital in February 2017. The final version of the questionnaire was confirmed after discussion with the participants and researchers. None of the 10 pregnant women validating the questionnaire participated in the study. No patients were involved in the selection of outcome measures or in the recruitment of participants.

\section{Inclusion/Exclusion criteria}

This study includes pregnant women who had deliveries at our research centre. It was mandatory to retrieve written consent from all participants during their stay in the hospital for deliveries. The inclusion criteria were as follows: singleton pregnancy; good status without severe complications influencing daily activities; an intact uterine cervix; and detailed and complete information from medical records on pregnancy, perinatal outcomes and infant follow-up. The exclusion criteria are listed in box 1. All participants were assured the information they provided will be strictly secured whether or not they take part in the investigation.

From March to June 2017, based on original recruitment, inclusion criteria and medical records, we sent online questionnaires through a Chinese social media application (WeChat) to participants to collect data on their experiences of postpartum sexual intercourse and contraceptive plans, and were quested on-site retrieval to ensure a proper correspondence rate. Data were included only if all items were specifically addressed.

\section{Questionnaire}

The final version of the questionnaire was modified and approved with a total and separate Cronbach's $\alpha$ $>0.600$ and Kaiser-Meyer-Olkin (KMO) measures $>0.700$ in the preliminary study. The questionnaire consisted of 20 items (online supplementary appendix 1) on (1) epidemiological data; (2) experiences, frequencies and complaints about sexual intercourse during pregnancy

\section{Box 1 Exclusion criteria of this study}

1. Divorce or separation of partners.

2. Incomplete information on pregnancy, perinatal period and infant follow-up.

3. Fetal complications.

- Major congenital malformation.

- Multiple pregnancy.

- Abortion or threatened abortion.

- Clinical presentations suggesting threatened premature labour.

4. Maternal complications.

- Uterine rupture or threatened uterine rupture.

- History of preterm pregnancy or recurrent pregnancy loss.

- History of conisation, loop electrosurgical excision procedure or radical trachelectomy.

- Severe vulvar and vaginal lesions of infections (condyloma acuminatum, Bartholin abscess).

- Congenital heart disease or any pathological disease of the cardiovascular system.

- Pneumothorax, pneumonia or any disease restricted to the respiratory system.

- Anaemia, thrombocytopaenia and other haematological disease.

- Myasthenia gravis.

- Mental disease.

- Cervical precancerous lesions and cervical cancer.

- Unexplained vaginal bleeding in the first trimester.

5. Placental abnormalities.

- Placenta previa or low-lying placenta.

- Placenta accreta.

and postpartum period; (3) practical and desired application of contraceptive methods; (4) reasons for not using contraception; and (5) other issues, including physical exercise, resumption of regular menstruation, depressive mood and cosleeping with the infant. Sexual intercourse was defined as vaginal intercourse of partners rather than other sexual behaviours (eg, non-entry intercourse, masturbation). Physical exercise was defined as a moderate to strong intensity of exercise at least three times per week for $30 \mathrm{~min}$ each. In our study, the reasons for not using contraception were as follows: fear that postpartum contraception would impair breast feeding, no knowledge on postpartum contraception, feeling no need to undergo rigorous postpartum contraception, no offer to the desired postpartum contraception and other problems (open options).

\section{Data collection}

We collected data from medical records and completed questionnaires using Microsoft Office Excel tables (online supplementary appendices 1 and 2). The following data were collected by retrospectively reviewing participants' and neonatal electronic medical records (created by DT Health 6.9.4, 2011 DT Health): epidemiological data, delivery modes and pregnancy complications, and perinatal outcomes of the mother and the newborn. Puerperal conditions beyond the electronic medical records (wound infections and endometritis) were verified 
through participants' complaints on medical records from outpatient clinics and/or the emergency room.

\section{Measures}

Primary measures consisted of resumption of sexual intercourse post partum and use of practical contraceptive methods. Secondary measures included (1) influencing factors on resumption of sexual intercourse within 3 months after delivery and (2) influencing factors on utilisation of contraceptive methods.

\section{Statistical analysis}

SPSS V.22.0 statistical software was employed for data analysis. We analysed continuous variables with t-test and categorical variables with $\chi^{2}$ test or Fisher's exact test. Multiple-parameter analysis was performed using binary logistic analysis, calculating the OR and 95\% CI to adjust for confounding factors, including all covariates with statistical significance shown in table 1 in a stepwise decision-making process. The reliability and validity of the questionnaire were evaluated using the Cronbach's $\alpha$ method and KMO measures/Bartlett's test of sphericity, respectively, for construct validity in the formal study.

\section{RESULTS}

\section{Participants}

From March 2016 to December 2016, 1466 pregnant women delivered at the study hospital. Based on the inclusion and exclusion criteria, we sent questionnaires to 550 eligible women, and $406(73.8 \%)$ responded and presented their written consent. The average age and gestational week at delivery were $31 \pm 4.1$ years and $39 \pm 1.2$ weeks, respectively. The median postpartum period was 8.5 months (range 6-10). Nearly half of the participants (195 cases, $48 \%)$ had deliveries via caesarean section. Exclusive breast feeding, mixed feeding and artificial feeding were observed in $345(85.0 \%), 52(12.8 \%)$ and 9 (2.2\%) women, respectively.

Among the participants, $279(68.7 \%)$ resumed sexual intercourse after delivery and $259(92.8 \%)$ used contraception. One hundred and eleven participants (27.3\%) reported various reasons for not using contraception: fear that postpartum contraception would impair breast feeding (65 women), no knowledge on postpartum contraception (47 women), feeling no need to undergo rigorous postpartum contraception ( 55 women) and no offer to the desired postpartum contraception (21 women).

\section{Reliability and validity of the questionnaire}

Most items on the questionnaire, especially items pertaining to experience and frequency of sexual intercourse and utilisation of contraceptive methods, had good or acceptable reliability (Cronbach's $\alpha>0.600$ ) and construct validity (KMO measures $>0.700$ ). Nevertheless, three items in our study had poor reliability and validity, namely postpartum complaints about the intercourse
(Cronbach's $\alpha=0.520, \mathrm{KMO}$ measures=0.511), resumption of regular physical exercise (Cronbach's $\alpha=0.504$, $\mathrm{KMO}$ measures $=0.610$ ) and feeling of depression within 3 months after delivery (Cronbach's $\alpha=0.600$, KMO measures $=0.423$ ).

\section{Resumption of sexual intercourse post partum in total and within 3 months}

One hundred and forty-six of 406 (36.0\%) women resumed sexual intercourse within 3 months and 133 of $260(51.2 \%)$ after 3 months $(\mathrm{p}<0.001)$. No significance existed between the proportion of women who resumed sexual intercourse within 6 months or during the whole postpartum period (all $\mathrm{p}$ values $>0.05$ ). The frequency and complaints about postpartum sexual intercourse are shown in table 2. The total and individual complaints were not significantly different between women who resumed sexual intercourse within 3 months and those who resumed sexual intercourse after 3 months (all $\mathrm{p}$ values $>0.05$ ). Among 127 women without postpartum sexual intercourse, $67(52.76 \%)$ reported lack of sexual interest.

\section{Potential factors affecting resumption of sexual intercourse within 3 months after delivery}

Potential factors impacting the resumption of sexual intercourse within 3 months are listed in table 1. Among all the 406 cases, in the multivariate analysis, sexual intercourse during pregnancy (adjusted OR 4.4, 95\% CI 2.8 to $6.9, \mathrm{p}<0.001)$ and resumption of menstruation after childbirth (adjusted OR 2.5, 95\% CI 1.5 to 4.3 , p<0.001) were included as covariates and were also significant influencing factors for resumption of sexual intercourse within 3 months after childbirth. However, age, delivery mode, maternal or neonatal outcome, breastfeeding manner, mood status, and physical exercise had no impact on resumption of sexual intercourse within 3 months. Neither sexual intercourse during pregnancy nor resumption of menstruation had impact on resumption of sexual intercourse within 6 months or other periods.

\section{Contraceptive methods used}

Among 279 women who resumed sexual intercourse after delivery, 259 (92.8\%) used contraception. No significant differences were evident for all variables listed in table 1 between women with and without contraception (all $\mathrm{p}$ values $>0.05$ ). The actual and desired contraceptive methods are listed in table 3. Compared with actual usage, more postpartum women desired the use of subdermal implants, intrauterine device (IUD) or oral contraceptive pills, and less postpartum women desired the use of a condom, coitus interruptus or no contraception.

\section{DISCUSSION}

In this study, we have described the detailed patterns of postpartum sexual intercourse and contraception and provided an analysis of the relevant factors. However, 
Table 1 Demographic characteristics of participants with or without postpartum sexual activities within 3 months after childbirth

\begin{tabular}{|c|c|c|c|}
\hline & \multicolumn{2}{|c|}{$\begin{array}{l}\text { Postpartum sexual activity within } 3 \text { months after } \\
\text { childbirth }\end{array}$} & \multirow[b]{2}{*}{ P value* } \\
\hline & No $(n=260)$ & Yes $(n=146)$ & \\
\hline Age (years) (mean $\pm S D)$ & $31.6 \pm 4.1$ & $30.1 \pm 4.2$ & 0.744 \\
\hline Sexual intercourse during pregnancy & $102(39.2 \%)$ & $109(74.7 \%)$ & $<0.001$ \\
\hline Educational level & & & 0.723 \\
\hline High school or below & $27(10.4 \%)$ & $19(13.0 \%)$ & \\
\hline College & $166(63.8 \%)$ & $90(61.6 \%)$ & \\
\hline Graduate degree or above & $67(25.8 \%)$ & $37(25.3 \%)$ & \\
\hline Income (¥) & & & 0.976 \\
\hline Low income $(<10000)$ & $154(59.2 \%)$ & $88(60.3 \%)$ & \\
\hline Middle income (10000-20 000) & $81(31.2 \%)$ & $44(30.1 \%)$ & \\
\hline High income (>20000) & 25 (9.6\%) & $14(9.6 \%)$ & \\
\hline Delivery mode & & & 0.816 \\
\hline Caesarean section & $126(48.5 \%)$ & $69(47.3 \%)$ & \\
\hline Vaginal delivery & $134(51.5 \%)$ & $77(52.7 \%)$ & \\
\hline \multicolumn{4}{|l|}{ Conditions during vaginal delivery } \\
\hline Application of vacuum extraction & $4 / 134(3.1 \%)$ & $4 / 77(5.3 \%)$ & 0.467 \\
\hline Episiotomy & $86 / 134(64.2 \%)$ & 49/77 (63.6\%) & 0.937 \\
\hline Perineal laceration & 48/134 (35.8\%) & $22 / 77(28.6 \%)$ & 0.282 \\
\hline \multicolumn{4}{|l|}{ Maternal outcomes } \\
\hline PROM & $48(18.5 \%)$ & $28(19.2 \%)$ & 0.859 \\
\hline Postpartum haemorrhage & $22(8.5 \%)$ & $11(7.5 \%)$ & 0.743 \\
\hline Infection of CS incision & $2 / 126(1.6 \%)$ & $1 / 69(1.4 \%)$ & 1.000 \\
\hline Infection of vulvar incision & 6/134 (4.5\%) & $4 / 77(5.2 \%)$ & 1.000 \\
\hline Puerperal endometritis & $18(6.9 \%)$ & $6(4.1 \%)$ & 0.249 \\
\hline Neonatal admission to NICU & $22(8.5 \%)$ & $14(9.6 \%)$ & 0.701 \\
\hline \multicolumn{4}{|l|}{ Other conditions within 3 months } \\
\hline Resumption of menstruation & $36(13.8 \%)$ & $45(30.8 \%)$ & $<0.001$ \\
\hline Resumption of physical exercise & $91(35.0 \%)$ & $64(43.8 \%)$ & 0.079 \\
\hline Feeding manner & & & 0.192 \\
\hline Breast feeding & $216(83.1 \%)$ & $129(88.4 \%)$ & \\
\hline Mixed feeding $†$ & $39(15.0 \%)$ & $13(8.9 \%)$ & \\
\hline Bottle feeding & $5(1.9 \%)$ & $4(2.7 \%)$ & \\
\hline Always feeling depression & $125(48.1 \%)$ & $60(41.1 \%)$ & 0.175 \\
\hline Sleeping with infants & $210(80.8 \%)$ & $120(82.2 \%)$ & 0.724 \\
\hline
\end{tabular}

*Continuous variables are compared with t-test and categorical variables with $\chi^{2}$ test or Fisher's exact test.

†Mixed feeding denotes a combination of breast and bottle feeding.

CS, caesarean section; NICU, neonatal intensive care unit; PROM, premature rupture of membranes.

only one-third of the generally healthy women resumed sexual activity within 3 months after delivery, in contrast to previous reports in which the resumption rate of postpartum sexual intercourse ranged from $48.2 \%$ to $73.1 \%$ within 2 months after delivery. ${ }^{14} 15$ The definitive reasons for this discrepancy are unknown. Resumption of sexual activity post partum was regarded as a vital aspect of sexual health and function, and routine postnatal consultation was an opportunity to identify altered sexual health patterns and counsel women accordingly, ${ }^{16}$ which may contribute to improved postpartum sexual activity.

We report that sexual activity during pregnancy, earlier resumption of menstruation and unrestricted access to contraception were independent factors associated with 
Table 2 Frequency and complaints about postpartum sexual intercourse

\begin{tabular}{lc}
\hline & $\mathbf{n}(\%)$ \\
\hline $\begin{array}{lc}\text { Frequency of sexual intercourse per month } \\
\text { Less than once }\end{array}$ & $72(25.8)$ \\
\hline $1-2$ & $122(43.7)$ \\
\hline $3-4$ & $63(22.6)$ \\
\hline 4 & $22(7.9)$ \\
\hline Complaints about postpartum intercourse & \\
\hline No sexual interest & $76(27.2)$ \\
\hline Pain during intercourse & $90(32.3)$ \\
\hline No arousal or orgasm & $30(10.8)$ \\
\hline Vaginal dryness & $7(2.5)$ \\
\hline Vaginal bleeding & $2(0.7)$ \\
\hline
\end{tabular}

resumption of sexual intercourse within 3 months after delivery, while delivery modes, incision issues, maternal/ neonatal outcomes, epidemiological factors and breast feeding have no impact. The relationship between sexual activities during pregnancy with postpartum sex is in dispute. According to the study of Yildiz, ${ }^{17}$ there was no relation between pregnancy and postpartum sexuality, and majority of women had a significant level of sexual dysfunction in the postpartum period. In our study, sexual activities during pregnancy did not influence postpartum sexual activities, except for sex within 3 months after delivery. The potential significance deserves further exploration.

Reported associations between caesarean delivery and sexual dysfunction are inconsistent. In a randomised controlled trial, delivery modes had no association with the proportion of individuals who had postpartum sexual intercourse. ${ }^{18}$ In a previous report, depressive symptoms, having a caesarean section and high maternal education were correlated with dysfunctional problems in several subdomains of the Female Sexual Function Index. ${ }^{19}$ Lactating women without sexual desire had lower levels of hormones. ${ }^{20-22}$ Oestrogen plays a critical role in mood and cognitive regulation. ${ }^{21}$ Hence, menstrual resumption may be associated with the level of oestrogen and progesterone and has an impact on postpartum sexual intercourse. Additionally, perineal trauma and the use of obstetric instrumentation are reported factors associated with the frequency or severity of postpartum dyspareunia, ${ }^{23-25}$ while different types of episiotomy have no impact on the quality of sexual life and perception of perineal pain. ${ }^{26}$ In the West Berkshire perineal management trial, $37 \%$ of women allocated to a group with restrictive use of episiotomy and $27 \%$ of women allocated to the routine-use group resumed sexual activity by 1 month after birth $(\mathrm{p}<0.01) .{ }^{27}$ However, the proportion of women who resumed intercourse by 3 months, had dyspareunia at 3 months or any dyspareunia within 3 months did not differ between groups. ${ }^{27}$

Few studies have reported on the effects of specifically relevant factors such as using contraception on postpartum sexual activity. Most reports are primarily concerned with comparing the immediate and delayed insertion of an IUD. However, the evidence base for IUD promotion in low-income and middle-income countries was weak and offered few lessons on what strategies are most effective. ${ }^{28}$ Home dispensing of hormonal contraceptives may improve the use of postpartum contraceptives by women. ${ }^{29}$ In our study, considerations about using contraception varied among postpartum women. These findings suggest that reducing related obstacles to facilitate access to contraception for postpartum women is reasonable. Given the paucity of high-quality evidence on the impact of hormonal contraception on breastfeeding outcomes and the strong evidence for improved health outcomes with the achievement of recommended birth spacing intervals, the real risk of unintended pregnancy and its consequences must not be neglected for fear of potential neonatal risks. ${ }^{30}$ Practical systematic support should be in place to ensure that women who desire long-acting reversible contraception or any other form of contraception can receive it during the comprehensive postpartum visit. ${ }^{31}$

Table 3 Actual and desired contraceptive methods

\begin{tabular}{|c|c|c|c|c|}
\hline & \multirow{2}{*}{$\begin{array}{l}\text { Actual contraceptive } \\
\text { methods among women } \\
\text { with postpartum sexual } \\
\text { intercourse }(n=279)\end{array}$} & \multicolumn{3}{|l|}{ Desired contraception } \\
\hline & & $\begin{array}{l}\text { Among women with } \\
\text { postpartum sexual } \\
\text { intercourse ( } n=279)\end{array}$ & $\begin{array}{l}\text { Among women without } \\
\text { postpartum sexual } \\
\text { intercourse }(n=127)\end{array}$ & Total $(\mathrm{N}=406)$ \\
\hline Condom & $210(75.3 \%)$ & $170(60.9 \%)$ & $80(63.0 \%)$ & $250(61.6 \%)$ \\
\hline Coitus interruptus & $42(15.1 \%)$ & 28 (10.0\%) & $12(9.4 \%)$ & $40(9.9 \%)$ \\
\hline Subdermal implant & $1(0.4 \%)$ & $28(10.0 \%)$ & $13(10.2 \%)$ & $41(10.1 \%)$ \\
\hline $\mathrm{OCP}$ & $3(1.1 \%)$ & $14(5.0 \%)$ & $8(6.3 \%)$ & $22(5.4 \%)$ \\
\hline No contraception & $20(7.2 \%)$ & $10(3.6 \%)$ & $5(3.9 \%)$ & $15(3.7 \%)$ \\
\hline
\end{tabular}

IUD, intrauterine device; OCP, contraceptive pill/oral contraceptives. 
Although knowledge gap exists, we have demonstrated that more Chinese women choose long-term contraception, including IUDs and subdermal implants. Longacting reversible contraceptives (LARC) have been recommended for postpartum contraception, ${ }^{32} 33$ as LARC can reduce periodic visits for populations in which regular medical care is inconvenient and can reduce the burden of unintended pregnancy. ${ }^{34}$ Moreover, clinical evidence suggests that IUDs and implants can be inserted within 48 hours post partum. ${ }^{35} 36$ Nevertheless, in our study, approximately one-fourth of women $(27.3 \%)$ had any reason of not using contraception. These findings warrant further education programme for postpartum women to achieve accessible, safe and effective contraceptive methods. Accessible contraception and essential knowledge can improve postpartum sexual activity and utilisation of contraception. The official recognition of the 'lactational amenorrhea method (LAM)' in the Bellagio consensus ${ }^{37}$ has been proven effective in a number of settings. ${ }^{38}$ However, a Cochrane meta-analysis did not find clear differences in the life table analysis of pregnancy rates between women using LAM and being supported in doing so, and fully breastfeeding women with amenorrhoea not using any method. ${ }^{39}$ Considering the unknown pregnancy risk, we did not recommend LAM as a usual method of contraception.

This study has several limitations. First, there were recall and selection biases originating from enrolment of participants. Second, the questionnaire could not assess the delicate cultural background, partners' relationship or newborn care, and thus the assessment may have missed potential reasons for declining sexual activity and contraception. The design lacked detailed information on sexual function and satisfaction. Third, we limited our study to generally healthy pregnant women. More attention and concern for sexual health are needed for all women, especially women with severe comorbidities. Access to safe sexual activity is an essential component of equality in human rights. Fourth, we did not consider pelvic floor function in this study. Fifth, we did not provide any evidence on the role of postpartum intercourse in the improvement of sexual health and well-being of women and intimacy between partners. Last but not the least, we limit the definition of sex to vaginal-penile intercourse. The reason is mainly to assess for the risk of unintended pregnancy as Sok et att had described. The secondary reason is the traditional cultural bondage in China. Women were somewhat abashed with regard to the topic of sex during our work, and a little more deep discussion about other sexual activities is refused by almost all the participants. Indeed, as McDonald and Brown ${ }^{41}$ noted, 'sexual activity' in a broad definition was resumed more quickly and more frequently than vaginal-penile intercourse immediately post partum.

In conclusion, having sexual intercourse during pregnancy and resuming menstruation earlier were independent factors for resumption of sexual intercourse within 3 months after delivery. Almost all women with postpartum sexual intercourse used various contraceptive methods, and no predictor was found to be associated with using contraception. More postpartum women needed longterm contraceptive methods.

Acknowledgements Great thanks to our participants for their intensive and friendly share.

Contributors All authors meet the ICMJE criteria for authorship: LL conceived of the original idea for the study, interpreted the results, carried out the statistical analysis, drafted the paper and is the overall guarantor. $\mathrm{CZ}$ designed the questionnaire, obtained ethical approval, contributed to the preparation of the data set, interpreted the results and contributed to drafts of the paper. TL contributed to study design, interpretation of the results and commented on drafts of the paper. CZ and TL contributed equally to the manuscript.

Funding The authors have not declared a specific grant for this research from any funding agency in the public, commercial or not-for-profit sectors.

Disclaimer The paper is not under consideration in another journal, and there have been no previous presentations and/or publications that used the same material in this paper.

Competing interests None declared.

Patient consent for publication Obtained.

Ethics approval The Institutional Review Board of the research hospital approved this study.

Provenance and peer review Not commissioned; externally peer reviewed.

Data sharing statement No additional data are available.

Open access This is an open access article distributed in accordance with the Creative Commons Attribution Non Commercial (CC BY-NC 4.0) license, which permits others to distribute, remix, adapt, build upon this work non-commercially, and license their derivative works on different terms, provided the original work is properly cited, appropriate credit is given, any changes made indicated, and the use is non-commercial. See: http://creativecommons.org/licenses/by-nc/4.0/.

\section{REFERENCES}

1. Glazener CM. Sexual function after childbirth: women's experiences, persistent morbidity and lack of professional recognition. $\mathrm{Br} \mathrm{J}$ Obstet Gynaecol 1997;104:330-5.

2. Johannes $\mathrm{CB}$, Clayton $\mathrm{AH}$, Odom DM, et al. Distressing sexual problems in United States women revisited: prevalence after accounting for depression. J Clin Psychiatry 2009;70:1698-706.

3. O'Malley D, Higgins A, Smith V. Postpartum sexual health: a principle-based concept analysis. J Adv Nurs 2015;71:2247-57.

4. Chivers ML, Pittini R, Grigoriadis S, et al. The relationship between sexual functioning and depressive symptomatology in postpartum women: a pilot study. J Sex Med 2011;8:792-9.

5. van Gent MD, Romijn LM, van Santen KE, et al. Nerve-sparing radical hysterectomy versus conventional radical hysterectomy in early-stage cervical cancer. A systematic review and meta-analysis of survival and quality of life. Maturitas 2016;94:30-8.

6. Maxwell SM, Colls P, Hodes-Wertz B, et al. Why do euploid embryos miscarry? A case-control study comparing the rate of aneuploidy within presumed euploid embryos that resulted in miscarriage or live birth using next-generation sequencing. Fertil Steril 2016;106:1414-9.

7. Sanses TV, Hanley JM, Zhang P, et al. Readmission and prolapse recurrence after abdominal and vaginal apical suspensions in older women. Obstet Gynecol 2016;128:1369-77.

8. Schreiber CA, Chavez V, Whittaker PG, et al. Treatment decisions at the time of miscarriage diagnosis. Obstet Gynecol 2016;128:1347-56.

9. Ethics Committee of the American Society for Reproductive Medicine. Electronic address: ASRM@asrm.orgEthics Committee of the American Society for Reproductive Medicine. Cross-border reproductive care: an ethics committee opinion. Fertil Steril 2016;106:1627-33.

10. Sedgh G, Singh S, Hussain R. Intended and unintended pregnancies worldwide in 2012 and recent trends. Stud Fam Plann 2014;45:301-14.

11. Huang $\mathrm{Y}$, Merkatz R, Zhu H, et al. The free perinatal/postpartum contraceptive services project for migrant women in Shanghai: 
effects on the incidence of unintended pregnancy. Contraception 2014;89:521-7.

12. Chang SR, Chang TC, Chen KH, et al. Sexual function in women 3 days and 6 weeks after childbirth: a prospective longitudinal study using the Taiwan version of the Female Sexual Function Index. J Sex Med 2010;7:3946-56.

13. Lee JT, Tsai JL. Transtheoretical model-based postpartum sexual health education program improves women's sexual behaviors and sexual health. J Sex Med 2012;9:986-96.

14. Susser LC, Sansone SA, Hermann AD. Selective serotonin reuptake inhibitors for depression in pregnancy. Am J Obstet Gynecol 2016;215:722-30.

15. Machin SE, Mukhopadhyay S. Pelvic organ prolapse: review of the aetiology, presentation, diagnosis and management. Menopause Int 2011;17:132-6.

16. O'Malley D, Smith V. Altered sexual health after childbirth: Part 2. Pract Midwife 2013;16:27-9.

17. Yıldız H. The relation between prepregnancy sexuality and sexual function during pregnancy and the postpartum period: a prospective study. J Sex Marital Ther 2015;41:49-59.

18. Hutton EK, Hannah ME, Ross S, et al. Maternal outcomes at 3 months after planned caesarean section versus planned vaginal birth for twin pregnancies in the Twin Birth Study: a randomised controlled trial. BJOG 2015;122:1653-62.

19. Wallwiener S, Müller M, Doster A, et al. Sexual activity and sexual dysfunction of women in the perinatal period: a longitudinal study. Arch Gynecol Obstet 2017;295:873-83.

20. Files JA, Kransdorf LN, Ko M, et al. Bioidentical hormone therapy: an assessment of provider knowledge. Maturitas 2016;94:46-51.

21. Srinivas SK, Small DS, Macheras M, et al. Evaluating the impact of the laborist model of obstetric care on maternal and neonatal outcomes. Am J Obstet Gynecol 2016;215:770.e1-70.

22. Brtnicka $H$, Weiss $P$, Zverina J. Human sexuality during pregnancy and the postpartum period. Bratis/ Lek Listy 2009;110:427-31.

23. Signorello LB, Harlow BL, Chekos AK, et al. Postpartum sexual functioning and its relationship to perineal trauma: a retrospective cohort study of primiparous women. Am J Obstet Gynecol 2001;184:881-90. discussion 888-90.

24. Klein MC, Kaczorowski J, Firoz T, et al. A comparison of urinary and sexual outcomes in women experiencing vaginal and Caesarean births. J Obstet Gynaecol Can 2005;27:332-9.

25. Hartmann $\mathrm{K}$, Viswanathan $\mathrm{M}$, Palmieri R, et al. Outcomes of routine episiotomy: a systematic review. JAMA 2005;293:2141-8.

26. Necesalova P, Karbanova J, Rusavy Z, et al. Mediolateral versus lateral episiotomy and their effect on postpartum coital activity and dyspareunia rate 3 and 6 months postpartum. Sex Reprod Healthc 2016:8:25-30.

27. Sleep J, Grant A, Garcia J, et al. West Berkshire perineal management trial. Br Med J 1984;289:587-90.

28. Cleland J, Ali M, Benova L, et al. The promotion of intrauterine contraception in low- and middle-income countries: a narrative review. Contraception 2017;95:519-28.

29. Melnick AL, Rdesinski RE, Marino M, et al. Randomized controlled trial of home-based hormonal contraceptive dispensing for women at risk of unintended pregnancy. Perspect Sex Reprod Health 2016;48:93-9.

30. Sridhar A, Salcedo J. Optimizing maternal and neonatal outcomes with postpartum contraception: impact on breastfeeding and birth spacing. Matern Health Neonatol Perinatol 2017;3:1.

31. American College of Obstetricians and Gynecologists' Committee on Obstetric Practice, Association of Women's Health, Obstetric and Neonatal Nurses. Committee opinion no. 666: optimizing postpartum care. Obstet Gynecol 2016;127:e187-92.

32. Raccah-Tebeka B, Plu-Bureau G. [Post-partum contraception: guidelines for clinical practice]. J Gynecol Obstet Biol Reprod 2015:44:1127-34.

33. Man J, Hutchinson JC, Heazell AE, et al. Stillbirth and intrauterine fetal death: factors affecting determination of cause of death at autopsy. Ultrasound Obstet Gynecol 2016;48:566-73.

34. Winner B, Peipert JF, Zhao Q, et al. Effectiveness of long-acting reversible contraception. N Engl J Med 2012;366:1998-2007.

35. Wong AH, Combellick J, Wispelwey BA, et al. The patient care paradox: an interprofessional qualitative study of agitated patient care in the emergency department. Acad Emerg Med 2017;24.

36. Sothornwit J, Werawatakul Y, Kaewrudee S, et al. Immediate versus delayed postpartum insertion of contraceptive implant for contraception. Cochrane Database Syst Rev 2017;4:CD011913.

37. Breastfeeding as a family planning method. Lancet 1988;2:1204-5.

38. The World Health Organization multinational study of breast-feeding and lactational amenorrhea. III. Pregnancy during breast-feeding. World Health Organization Task Force on Methods for the Natural Regulation of Fertility. Fertil Steril 1999;72:431-40.

39. Van der Wijden C, Manion C. Lactational amenorrhoea method for family planning. Cochrane Database Syst Rev 2015:CD001329.

40. Sok C, Sanders JN, Saltzman HM, et al. Sexual behavior, satisfaction, and contraceptive use among postpartum women. $J$ Midwifery Womens Health 2016;61:158-65.

41. McDonald EA, Brown SJ. Does method of birth make a difference to when women resume sex after childbirth? BJOG 2013;120:823-30. 